\title{
Dramaturgia na Dança: manipulação de energia no processo
}

\author{
Veronica Fabrini Machado de Almeida \\ Universidade Estadual de Campinas - UNICAMP, Campinas, Brasil \\ E-mail: vefabrini@gmail.com \\ Melina Scialom \\ Universidade Estadual de Campinas - UNICAMP, Campinas, Brasil \\ E-mail: melinascialom@gmail.com
}

Resumo

A entrada do conceito de dramaturgia no campo da dança traz a chance de revisitarmos o termo para trabalharmos com sua prática e conceituação na contemporaneidade. Com o foco sobre a dramaturgia do corpo e na dança, este artigo propõe-se a discutir o termo a partir da investigação prática que aconteceu durante um encontro entre artistas-pesquisadores da área. Através de vivências práticas de dança moderna e contemporânea, dança-teatro e das manifestações populares brasileiras, entendemos a dramaturgia como uma manipulação de energia que acontece no processo de criação, incluindo o treinamento técnico do performer.

Palavras-chave

Dramaturgia da Dança. Energia.

Preparação Corporal.
Abstract

The introduction of the concept of dramaturgy within the dance field opens the possibility to revisit the term and work with its conceptualisation in contemporary practice. With the focus on dance and body dramaturgy, this paper aims to discuss the term based on an investigation that happened during a practice-based symposium of dance artist-researchers. Through the practice of modern and contemporary dance, dance-theatre and Brazilian popular culture, we drew an understanding of dramaturgy as a manipulation of energy that happens in the creative process, including the training of the performer.

Keywords

Dance Dramaturgy. Energy.

Performer Training. 


\section{Introdução}

Muito tem-se discutido sobre dramaturgia na dança e dramaturgia do corpo desde a virada do século $X X$ até as primeiras décadas do século $X X I$, tanto internacionalmente (HANSEN; CALLISON, 2015; CALDAS; GADELHA, 2016), quanto no Brasil (CORRADINI, 2010; VELLOSO, 2010; ALVIM, 2012; DORIA, 2016; MACEDO, 2016). Estes trabaIhos apontam que esta temática vem se expandindo para ser utilizada como referência de uma certa teatralidade ou mesmo de uma narratividade em diferentes linguagens artísticas, buscando assim inscrever um sentido pressentido para além das formas e movimentos. Sentido este, em sua dupla acepção do percebido e do inteligível, que exala da maneira como formas, movimentos e ações entretecem-se e se articulam no tempo.

O termo e a prática dramatúrgica vêm se firmando na dança, criando seu próprio espaço de existência e se diferenciando dos conceitos propriamente teatrais, associados ao termo, especialmente sobre aqueles diretamente relacionados ao texto escrito e a literatura dramática. Neste caso, cada vez mais o fazer dramatúrgico tem sido considerado, como ressalta Paulo Caldas e Ernesto Gadelha (2016), como uma prática compartilhada, um campo coativo onde o texto dá lugar a uma textura que passa a ser tecida, entrelaçada e suturada por corpos (em movimento) e presença cênica, sublinhando um olhar para o processual, antes mesmo do produto artístico final. Inclusive, a reflexão sobre dramaturgia na dança vem oferecendo novas abordagens ou perspectivas para aquilo que é considerado como dramatúrgico em um espetáculo (LEHMANN, 2007). Ao problematizar o fazer da dança envolvendo o treinamento do bailarino-ator e seus vieses dramatúrgicos, este artigo desenvolve um olhar para a dramaturgia do corpo e da dança não como esforço meramente taxonômico, mas no desejo de alimentar discussões a cerca das especificidades da criação na área. Para tanto, lança mão de uma breve reflexão teórica sobre o conceito de dramaturgia na dança para, em um segundo momento, refletir sobre os atravessamentos dramatúrgicos que acontecem em suas práticas. Tendo por base um evento da UNICAMP realizado no departamento de Artes Cênicas, no qual artistas-pesquisadores da dança vindos de diferentes formações expuseram suas práticas - técnicas composicionais - buscando evidenciar o que nelas seria uma perspectiva dramatúrgica.

\section{Dramaturgia na dança}

Ao se falar em dramaturgia na dança nosso primeiro impulso é de realizar uma associação com o teatro, cujo termo já estava presente desde a Grécia antiga, podendo ser conceituada na Poética de Aristóteles (2007) como a organização coerente das ações de um ator em cena, a fim de produzir e provocar, no público a kátharsis, ou seja, a purgação ou ainda, a purificação das emoções, especialmente o terror e a piedade ${ }^{1}$. Porém apesar da proximidade estética das linguagens da cena, a dramaturgia na dança tem oferecido perspectivas sobre o conceito que dialogam com seu fazer artístico particular. O estado de espírito dramatúrgico (DORT, 1986) está presente na dança desde a época do maître de ballet Jean-Georges Noverre, no século XVII, sendo também uma prática identificada na parceria entre coreógrafos e críticos durante todo século XX - como no caso de Pina Bausch e Raimund Hoghe; Martha Graham e John Martin (HANSEN, 2015). Já no século XXI, o termo dramatur-

\footnotetext{
1 Para discussões sobre a evolução do termo dramaturgia e do conceito de drama no teatro ver Roubine (2003); Saadi (2013); Szatkowski (2019); Szondi (2001).
} 
gia, tem sido amplamente tensionado nas práticas de dança, tanto no Brasil (ELIAS; TOURINHO, 2011; MORAES, 2012; MUNDIM, 2012; DORIA, 2016; SCIALOM, 2016) quanto no mundo (DELAHUNTA, 2000; BUTTERWORTH; WILDSCHUT, 2017; GEORGELOU; PROTOPAPA; THEODORIDOU, 2017). Inclusive, o conceito de dramaturgia tem facilitado uma discussão em torno da materialidade das práticas criativas em dança. Neste sentido a pesquisadora e dramaturga belga Marianne Kerkhove (1997) lembra que a dramaturgia na dança traz o foco sobre o processo de criação e não sobre um produto (contrapondo-se ao texto teatral que muitas vezes é escrito antes do processo de criação iniciar). Isto porque é da própria materialidade da linguagem da dança a criação acontecer a partir da fisicalidade dos dançarinos, na sala de ensaio onde o conceito da obra vai surgindo nos próprios desdobramentos que acontecem durante o processo de criação. Entender e lidar com essa particularidade que associa dramaturgia ao processo criativo é essencial ao se pensar o conceito e prática de dramaturgia na dança.

A pesquisadora francesa Laurence Louppe (2010) explica que a criação em dança está diretamente ligada ao seu processo, ou seja, ao treino, às aulas e a preparação do bailarino. Para a autora as aulas técnicas de dança já são um engajamento artístico em si pois os trabalhos corporais implicam em estéticas particulares relacionadas a elas. Desta forma, passaremos a trabalhar com a perspectiva de que: se a dramaturgia na dança está ligada à criação, ela também está associada ao treino, ao processo, ao ensaio e aos corpos em movimento.

Nesse contexto onde dramaturgia, criação e treino estão intimamente associados, Ana Carolina Mundim (2013) enfatiza que as aulas de dança tornam-se material significante no tecido de signos que devem ser articulados e organizados para dar sentido a obra, ou seja, sua dramaturgia. Assim, o trabalho técnico-criativo do artista influencia na criação da obra. Desse modo, aproximamo-nos do entendimento de que treinamento, criação e dramaturgia, em dança, estão interligados e iniciam no estúdio, no treinamento e na prática diária do performer ${ }^{2}$.

Considerando que o conceito de dramaturgia remete a uma espécie de organização ou tessitura de elementos, a fim de se criar um sentido para algo, (GREINER, 2000; BONFITTO, 2011) pensar o trabalho técnico do performer-bailarino é, também, dar início a um pensamento dramatúrgico no processo ${ }^{3}$. Justamente, Andre Lepecki esclarece que aquilo que nutre a dramaturgia na dança não está ligado ao espaço entre a escrita e a ação física, mas sim a "tensão estabelecida entre múltiplos processos de pensamento não-escritos" (2016, p. 64). São justamente estes processos de pensamento não-escritos que compõe a formação (treinamento) do dançarino.

A partir desse corolário de que o processo de criação em dança envolve o próprio treinamento (LOUPPE, 2010; DANTAS, 2005; MUNDIM, 2013), isto é, um contínuo que vai desde a sala de aula até os ensaios, propusemos buscar em diferentes práticas ou aulas onde estariam seus possíveis ganchos dramatúrgicos.

Seria possível perceber nas diferentes maneiras de engajar corpo, movimento e espaço, uma dramaturgia ou um modo sin-

\footnotetext{
2 Mesmo quando recorremos ao terreno do 'empréstimo' do termo dramaturgia do teatro, há nele também, talvez de forma menos evidente, um tecido que conecta treinamento e preparação do ator, com modos de criar e dramaturgias possíveis (ver BARBA, 1997; BONFITTO, 2011).

3 A dramaturgia no processo é diferente de "dramaturgia em processo". Isto porque de acordo com Antônio Araújo (2006, p. 129) a dramaturgia em processo designa um texto-objeto que está em fluxo contínuo de transformação, onde os ensaios transformam a dramaturgia continuamente, garantindo um "espaço de experimentação dramatúrgica” durante a criação.
} 
gular de organizar ações? Para realizar tal investigação reunimos diferentes artistas-pesquisadores com percursos de formação e prática cênica distintas, para discutirmos, de forma experimental (coletiva, prática e dialógica) o que seria uma dramaturgia na dança. Logo, a metodologia deste trabalho se pautou na Prática como Pesquisa ou Practice-as-Research, que prevê uma reflexão epistemológica realizada a partir da prática (fazer artístico e criativo) ou o que chamamos de pesquisa empírica Esta qual identifica a prática como domínio de conhecimento (NELSON, 2006), onde métodos e temas (de trabalho) atuam como objeto de análise e como ferramentas de investigação. Por isso, tomamos a experiência prática dos artistas-pesquisadores como fazeres epistemológicos no campo das artes cênicas e assim olhamos para o conhecimento gerado em suas aulas de forma crítico-analítica.

Ao assumirmos tal estratégia, convidamos Sayonara Pereira (professora do curso de Artes Cênicas da USP), Holly Cavrell (professora do curso de Dança da UNICAMP, coreógrafa e diretora da Cia. Domínio Público), Gustavo Ciríaco (bailarino e coreógrafo), Isabelle Dufau (coreógrafa e bailarina francesa) e Grácia Navarro (professora do departamento de Artes Cênicas da UNICAMP e diretora do grupo de pesquisa Pindorama) para compartilharem seus treinamentos, processos criativos, modos de composição e perspectivas sobre possíveis dramaturgias na dança. Cada um destes artistas ministrou uma oficina de duas horas para alunos do curso de graduação e pós graduação de teatro e dança, com a presença, em média, de 20 a 30 participantes, os quais experimentaram todas as cinco oficinas oferecidas, ao todo de três dias de atividades (duas oficinas nos primeiros dois dias e uma oficina no terceiro dia). Cada dia foi finalizado com uma roda de conversa. No final do tercei- ro dia, realizamos uma roda com todos os artistas, ministrantes e participantes para compartilharmos e debatermos - através da experiência que tivemos - o conceito de dramaturgia do corpo na dança. Foi através da prática (aulas de dança) que pudemos experimentar reflexões sobre linguagens/técnicas e criações que informaram os processos relacionados à organização (coreográfica) do movimento no espaço-tempo de cada artista. Por meio da própria ação, da pedagogia e da prática de dança, experimentamos e pensamos o movimento expressivo e suas possíveis conexões com a dramaturgia.

\section{Movimento, energia e dramaturgia}

Para discutir as práticas dos professores-artistas convidados, buscamos encontrar nos pontos congruentes de suas práticas a possível singularidade da dramaturgia na dança. A aula que cada um dos artistas ofereceu, refletiu sua história pessoal e seu percurso nas artes da cena: da dança moderna europeia (Isabelle Dufau) à dança moderna dos Estados Unidos (Holly Cavrell); da dança-teatro alemã (Sayonara Pereira) à dança-teatro brasileira (Grácia Navarro); finalizando na dança contemporânea e performática (Gustavo Ciríaco). Nestas aulas, experimentamos 'como' cada abordagem (seus procedimentos poéticos e sua estética) propõe organizações corporais particulares, trazendo ao dançarino determinados padrões de movimento e, consequentemente, diferentes estados de energia corporal. A experiência com a variedade, com manipulações do corpo e do movimento, levou-nos a perceber que quando estamos em

\footnotetext{
4 Jussara Muller explica que o estado de dança acontece quando o corpo em movimento age como um vetor de emoções não como emoções criadas, narradas, interpretadas e representadas, mas como consequência das memrias (psíquicas e físicas) que surgem com o corpo em movimento.
} 
"estados de dança" (MILLER, 2012, p. 117) passamos a organizar nosso movimento não como um 'texto' - ainda que no sentido de um alfabeto coreográfico - e menos ainda enquanto significados com referentes externos, mas como energia dinâmica, gerada a partir da relação do corpo com o espaço (em suas articulações com o tempo, peso e fluência) e em relação a outros corpos ou objetos. Por isso, deixamos de associar as manipulações do corpo e do movimento com significados ou textos para olharmos ao material como um tipo de energia, a qual emerge a partir do movimento que acontece em um corpo em relação a si próprio, com o espaço, com o outro e com um objeto.

O termo 'energia' tem reverberações particulares tanto na dança quanto no universo teatral. O artista e filósofo Rudolf Laban chamou de energia as variações dinâmicas (qualitativas) e relacionais (do corpo em movimento) e as nomeou de: teoria dos Esforços (Efforts) ou Eucinética (LABAN, 1978). Nesse contexto, Paola Crespi (em CRESPI; MANGHANI, 2015) esclarece que está implícito na práxis de Laban que a Eucinética inclui tanto o gasto/produção/ movimentação de energia (quando o corpo se move) quanto uma força criativa primitiva, que seria o impulso interior que gera o movimento. Estas, quando sequenciadas ou 'fraseadas' trazem determinadas nuances ou significados para o movimento. Assim, Laban apontava o elo entre prática, composição e dramaturgia. Já no universo teatral, Michael Chekhov chama de energia as qualidades de movimento que compõem a expressão do ator ou a "força vital" de um corpo (PETIT, 2010), apoiando-se no pensamento da Antroposofia de Rudolf Steiner.

\footnotetext{
5 É importante lembrar que Barba não separa a dança do teatro. Como na cultura popular, dança e teatro estão juntos, na mesma manifestação cênica: "por teatro Barba se refere inclusivamente tanto ao teatro quanto a dança". (2004, p. 48).
}

Já Eugenio Barba (1994) esclarece que para o ator a energia está relacionada com sua presença cênica ou seja no 'como' ele está presente: como se movimenta (energia no tempo) ou fica imóvel (energia no espaço) ${ }^{5}$.

Para gerar estados de energia Isabelle Dufau, em sua oficina, no evento em questão, trabalhou sobre os princípios e fatores do movimento (Eucinética), de acordo com a perspectiva de Rudolf Laban (ver LABAN, 1978). Ao trabalhar com os ritmos do corpo (a partir da respiração, das dinâmicas de expansão e recolhimento, direções espaciais, peso, tensões e o tamanho do movimento - cinesfera), ela sugeriu determinadas corporeidades envolvendo o uso de imagens. Por exemplo, em um de seus exercícios ela pediu que fizéssemos uma caminhada diferente: as pontas dos pés deveriam tocar o chão antes dos calcanhares, os braços deveriam permanecer ao longo do corpo - sem balançar, deslocando, assim, o foco da atenção para o movimento da parte inferior do corpo (pernas e pés). Ela seguiu investigando e propondo a aceleração e a desaceleração, fazendo com que os corpos dos participantes entrassem num estado físico de "como se estivessem caminhando sobre ovos" ${ }^{\text {, }}$ o que exigia um controle fino sobre a transferência de peso para que a fluência fosse mantida controlada. Isabelle chamou a atenção para que percebêssemos como espaço, tempo, peso/força e o fluxo atuam sobre a materialidade e sobre a experiência individual no/do movimento, tornando visível algo que inicialmente era invisível - nossos impulsos internos e o que passamos aqui a entender como energia.

Com esta experiência, percebemos que as mudanças nas qualidades de movimento atuam como alterações na energia corporal, modificando o corpo (forma), a intenção e suas tensões, chegando então a remodelar o

6 Fala de Isabelle durante sua oficina no evento, abril de 2017. 
tecido e a matéria deste corpo. Um corpo que por meio das mudanças das qualidades de movimento (rítmicas e espaciais) reverbera energia em si e para além, chegando até aos outros corpos (tanto os observadores quanto os dançantes), produzindo variações de energia que organizam as ações, gerando um determinado estado dramatúrgico do corpo.

Para Isabelle, o trabalho sobre os fatores do movimento (que criam e modificam a energia) permite que o dançarino não fique preso na ideia inicial do 'que' ele quis dizer, permitindo que aquele que está de fora (público) tenha autonomia para dar sentidos ao que está vendo. Ela explicou que "mesmo quando desprovido de um sentido, já tem um significado, já tem um histórico encarnado em sua forma, dinâmica e presença". Para esta artista, "a maneira com que o dançarino se coloca no espaço, organiza suas ações/movimentos e se relaciona com o público é uma escolha política", ou seja, uma posição particular dentro de algo compartilhado. No escopo que estamos abordando aqui é possível considerar, no sentido expandido do termo, que a presença e as escolhas estilísticas do dançarino se tornam uma atividade dramatúrgica.

As escolhas estilísticas da oficina de Holly Cavrell nos apontaram para uma outra experiência dramatúrgica. Com histórico de formação e pesquisa na dança moderna dos Estados Unidos, Holly trouxe um trabaIho embasado em princípios de movimento e expressão característicos desta herança, em especial sua formação e pesquisa nas técnicas desenvolvidas pelos dançarinos modernistas Martha Graham, Doris Humphrey e José Limon. De Graham, Holly traz o tronco como centro expressivo, a contração e o release como dinâmica geradora; de

7 Fala de Isabelle durante sua oficina no evento, abril de 2017. 8 Fala de Isabelle durante sua oficina no evento, abril de 2017.
Humphrey e Limón, a ênfase na queda e a recuperação, o uso dos ritmos gerados pela ação da gravidade e a respiração como fluxo de organicidade. Para além dos recursos técnicos, Holly introduziu, a complexidade da dimensão humana experienciada através do corpo. A experimentação que propôs levou-nos a corporificar a tradição expressiva moderna, através de diálogos com o contemporâneo. Por meio de exercícios técnicos de dança - no chão, no centro da sala e percorrendo as diagonais - Holly orientou nossa exploração dos princípios técnicos como os contrastes entre contração e expansão; queda e recuperação; tensão e relaxamento. Na dança moderna estes contrastes são incorporados como estratégias composicionais e, portanto, dramatúrgicas.

Para incentivar a corporeidade individual dos dançarinos, durante os exercícios que conduziu, Holly fez uso de imagens (que ela verbaliza) acompanhando cada movimento sugerido e por ela demonstrado. Estas imagens indicaram a intensidade e a qualidade do movimento, a serem incorporadas durante a prática, incentivando nossa descoberta de um corpo em deslocamento, acompanhado de respiração e peso, modificando assim nossos estados de energia.

A abordagem de Holly sobre o movimento a partir de imagens difere do trabalho de Isabelle pois esta opera a partir de qualidades (fatores) do movimento (como os de Laban).

Barba (1994, p. 77) explica que utilizar imagens para estimular a energia do performer alimenta o 'como' um movimento é realizado. Porém o autor reforça que o performer precisa transformar o 'como' em um 'que', ou seja, transformar uma substância impalpável em uma matéria que pode ser "manobrada, modelada, cultivada, projetada no espaço, absorvida e levada a dançar no interior do corpo", não como fantasias, mas como imaginações eficazes que geram corporei- 
dades e, portanto, energia corporal que são projetadas para o mundo. Nesta perspectiva, as imagens que Holly utilizou, em sua oficina, para nos sugerir qualidades e movimentos tornaram-se elementos dramatúrgicos na constituição de nossa corporeidade.

As imagens como elemento dramatúrgico também são a base do trabalho de Grácia Navarro e sua dança-teatro brasileira ${ }^{9}$. Com largo histórico de pesquisa em cultura popular, Grácia parte das imagens dos arquétipos presentes nas manifestações populares (religiosas e festivas) em conjunto com suas tensões com o campo político-social (através do olhar de uma artista da cena). Para exemplificar, Grácia mostrou-nos um documentário a respeito de uma de suas obras - Diário de Exus $^{10}$. Como uma das portas de entrada no território da cultura popular, Grácia trabalha tanto com a imagem quanto com os movimentos e corporeidades dos orixás da cultura brasileira, que atuam como matrizes energéticas e poéticas em suas práticas e criações, afirmando que, ainda que o praticante não seja um iniciado e desconheça a religião da qual se origina, a potência das corporeidades, movimentos, gestos e ritmos é tal que as diferentes qualidades de energias se impõem como conhecimento encarnado de cada arquétipo. Isso permite uma transfiguração poética realizada a partir de elementos simbólicos e experiência corporal do performer.

Esbarrando novamente na questão da energia, Grácia esclarece que, para trabalhar diferentes estados energéticos e construir corporeidades distintas, ela busca as características (sagradas, cênicas e tradicionais) de diferentes arquétipos. A energia provinda

9 Estamos chamando o trabalho de Grácia de 'dança-teatro brasileira' por nossa própria interpretação da pesquisa que realiza sobre as corporeidades presentes nas manifestações populares e o como ela mescla dança e teatro em espetáculos híbridos.

10 Diário de Exus, direção roteiro e Produção de Gilberto Alexandre Sobrinho, com concepção e pesquisa de Gilberto Alexandre Sobrinho e Grácia Navarro, UNICAMP, Campinas, 2014. dos arquétipos é seu "pontapé inicial" para a criação ${ }^{11}$. O jogo com os diferentes estados energéticos e com as relações emergentes entre eles cria o que ela chama de "dramaturgia no espaço entre" ou a dramaturgia do corpo em relação. Esta seria uma "dramaturgia como consequência"12, por sua vez, resultante das energias provindas dos arquétipos trabalhados. Estes arquétipos fazem parte também do que Mario de Andrade (1959) chamou de "danças dramáticas do Brasil": uma comunhão entre teatralidade, dança, música e artes visuais, o que tornou-se uma espécie de dança-teatro brasileira. Pudemos garimpar então, nesta oficina, as diferentes energias associadas e enraizadas no terreno arquetípico e social, como possibilidades de ferramentas dramatúrgicas.

Numa outra forma de articular dança e teatro, Sayonara Pereira trouxe sua experiência com a dança-teatro alemã (tanztheater), partindo de sua carreira como bailarina da companhia de dança da coreógrafa alemã Susanne Linke e sua formação da Folkwang Hochschule (atualmente Folkwang University of the Arts), escola onde Kurt Jooss (discípulo de Rudolf Laban) foi diretor durante muitos anos. Sayonara conduziu-nos em uma vivência que relacionou a busca pela expressividade do corpo, combinando movimentos abstratos com gestual cotidiano, sempre focados na exploração do fluxo, enfatizando a importância da precisão na execução de padrões de movimento. Para incentivar esta precisão e disparar nossa prática criativa, ela fez uso de cartões postais e fotos indicando para que fossem encontradas as histórias presentes em cada uma dessas imagens (visuais) e após, individualmente, transformamos tais histórias em

11 Palavras de Grácia Navarro durante sua oficina no evento, abril de 2017.

12 Palavras de Grácia Navarro durante sua oficina no evento, abril de 2017. 
movimento. Este exercício nos impulsionou a buscar qualidades expressivas para a criação de movimentos associados as memórias pessoais de cada participante. $O$ uso das imagens foi uma ferramenta para gerar estados energéticos no corpo. Deste exercício emergiram pequenas dramaturgias relacionadas à cada imagem, as quais foram apresentadas em uma mostra coletiva no final da oficina. O surgimento de diferentes dramaturgias a partir da coleção de imagens nos revelou o universo extenso de possibilidades que uma fotografia, pintura ou cartão postal pode ter. Desta maneira, quando uma pessoa interpreta e extrai as energias dispostas numa informação visual e transpõe para o corpo, está criando em sua performance individual um possível estado dramatúrgico.

Foi então que Gustavo Ciríaco mostrou, em sua oficina, que não só individualmente, mas a energia também pode ser manipulada em coletivo - articulando o que Barba conceitua como uma "energia desenvolvida pela espontaneidade e estados de alerta na performance" (TURNER, 2004, p. 27). Este tipo de energia, produzida de forma espontânea, contrapõe-se às sequências coreografadas que chegam aos atores e bailarinos previamente concebidas por um coreógrafo. Estas, por sua vez, correm o risco de amortecer os sentidos do ator/dançarino e estancar a circulação de energia, já que o intérprete realiza um esforço (mecânico) para aprender e apreender uma coreografia pronta e imaginada por outra pessoa. Tencionando o modelo de coreografias pré-concebidas, Gustavo iniciou sua oficina sem aviso ou formalidades, logo de início, ainda com os participantes sentados, esperando, alongando-se ou mesmo andando pelo espaço, começou a perguntar: "já começou? Quando começa?"13

13 Palavras de Gustavo Ciríaco durante sua oficina no evento, abril de 2017.
Para gerar e circular a energia, tanto nos corpos individuais quanto no coletivo, Gustavo atuou como um regente da cena: foi dando instruções enquanto o grupo de pessoas se movia, sem nenhuma preparação ou antecipação do que iria acontecer. Fomos nos movendo, modelando e remodelando (a partir das instruções recebidas em tempo real), sem pausas para explicação ou conceituação do que deveríamos fazer. Pensar e agir tornaram-se uma mesma ação - agir tornou-se o próprio pensar. Gustavo nos conduziu pela sala e para fora dela. Ocupamos o corredor do departamento de Artes Cênicas, saímos até a calçada e a rua do lado de fora do prédio no qual estávamos - sem que a energia do coletivo se dissipasse. Ele, com esta regência, manteve os nossos sentidos vivos a cada etapa do exercício, a cada surpresa gerada por um novo espaço ou por um incidente do acaso.

A proposta de Gustavo trouxe a possibilidade de um estado dramatúrgico do corpo o qual acontece no momento em que este se encontra em relação, que, no caso desta prática, veio tanto da proximidade com outros corpos quanto da mobilização interna, ou seja, aquela que cada um descobriu em si quando em situação de confronto (do seu próprio corpo com os espaços e com os elementos contidos no ambiente).

Estes diálogos (ou fluxos energéticos extraídos do movimento cotidiano) foram elementos para a composição que realizávamos em tempo real, enquanto Gustavo regia o coletivo. Esta proposta, portanto, contrapõe-se ao pensamento de Barba (1994) que prevê a performatividade do corpo do ator que prepara uma cena de antemão, gerando um estado específico para sua atuação. Todavia, Gustavo permite uma dramaturgia que se dá a partir de um jogo que emerge das relações produzidas no momento exato que acontecem, conferindo assim, nesta sua 
prática, uma característica que reforça uma dramaturgia (em sua dança) que acontece no processo - no momento em que a obra é composta e ao mesmo tempo executada.

Essa experiência com diferentes abordagens de trabalho nos levam a entender que diferentes energias (ou organizações energéticas) significam diferentes dramaturgias do corpo. Ao experimentarmos essas cinco práticas e seus modos de manipular energia através de diferentes corporeidades, percebemos que cada processo de treinamento reflete uma organização particular do corpo, do movimento e da presença do artista. Assim, essas oficinas permitiram que os participantes entendessem os estados de energia gerados através do movimento, concluindo que o termo estados de energia corporal se remete diretamente a um possível estado dramatúrgico do corpo.

\section{Dramaturgia no processo}

Nas discussões realizadas, durante o evento, diversos pontos foram levantados problematizando o termo Dramaturgia, com suas possíveis ramificações na área da dança. Pois foi por meio da prática (desde o treinamento do performer, até a livre composição) que os cinco artistas convidados tencionaram o termo dramaturgia do corpo e movimento, resultando em uma exploração da relação entre: técnica, geração de energia e composição/criação. Uma das tensões emergentes, durante as oficinas, foi que a dança 'pensa' diferente do teatro, uma diferença que é fundamental para compreender as particularidades entre essas duas áreas (quando relacionados ao uso do conceito de dramaturgia) pois é a partir desta diferença que o termo se expande e ao mesmo tempo se particulariza.

Para entendermos esta diferença entre dança e teatro, Gustavo (em sua ofici- na) realizou outro exercício: um aluno foi orientado a sair da sala, enquanto outro foi escolhido para ficar de pé, no centro da roda, segurando uma máscara, quando aquele que tinha saído, retornou, aconteceu uma cena espontânea entre os dois.

Quando o aluno que retorna à sala é um dançarino este dá pouca atenção para o signo que a máscara representa, ficando atento à colocação de seu corpo no espaço e na relação com o outro corpo em cena. Já no caso de um ator, sua atenção estaria presa na simbologia contida no objeto (máscara) e o utilizaria para estabelecer uma interação com ela (envolvendo mudança de voz, gestual, e intenções). Sobre isto o pesquisador alemão Hans-Thies Lehmann (2007) explica que, diferente do teatro, a dança tende a compor imagens corporais precisas, não se preocupando em formular sentidos mas articulando energia na forma de gestos e movimentos ${ }^{14}$.

Outro ponto que foi levantado, nas discussões, foi a relação entre: dramaturgia, expressividade e narratividade. No caso da dança, a priori, o movimento não narra uma cena, mas sempre traz algo de expressivo, propondo um olhar sobre o movimento que o diferencia (tanto da narração quanto da interpretação/ representação). Quando uma ação é desprovida desses três termos (vindos da herança teatral) resta somente corpo e energia. Citando Lehmann (2007, p. 158): "o corpo não expõe nada além de si mesmo, a renúncia à significação pelo corpo e a orientação para um corpo de gestos destituídos de sentido (dança, ritmo, graça, força, riqueza cinética) se revelam como o mais extremos fardo do corpo", mas que não deixa de ser expressivo.

Pensando nesta expressividade, Isabelle trouxe (em sua oficina) um jogo de possi-

\footnotetext{
14 Para Lehmann (2007), estas características da dança de não formular sentidos mas articular energia é que aproxima a dança das formas de que ele chama de teatro pós-dramático.
} 
bilidades de exploração com fatores do movimento (tempo, peso e fluxo) - lembrando que isto é chamado por Laban de 'energia' - modificando as qualidades do movimento dos dançarinos e portanto fazendo uma dramaturgia da cena. De fato, Lehmann (2007, p. 339) explica que "a realidade própria das tensões corporais, livre de sentido, toma o lugar da tensão dramática". Portanto, reforçamos que a dramaturgia na dança pode estar associada à produção e variação de energia.

Grácia acredita que a cultura popular e tradicional brasileira também trata dessa energia usando os arquétipos como chave para trabalhar suas variações em composições dramatúrgicas. Segundo Vitor Hugo Neves de Oliveira $(2014$, p. 8) a dramaturgia nas danças populares é "um jogo entre o mundo constituído e o mundo vivido, o que a torna uma esfera potencialmente situacional" onde estruturas míticas transformadas pela oralidade regem as estruturas dançantes $e$ seus padrões de movimento, atualizados por cada indivíduo presente no rito. Quando transpomos o pensamento de Lehmann (2007) a cerca da a dramaturgia como um arranjo de estados e situações, para o contexto das manifestações populares, prevemos uma dramaturgia do corpo "capaz de produzir contextos e sentidos, gerar sentimentos e emoções" (FURTADO, 2012, p. $3)$. Logo, dramaturgia e energia se encontram na materialidade do corpo do ator/ bailarino quando em estado de ação, em qualquer tipo de manifestação cênica. Ou seja, como energia, esta dramaturgia que acontece na prática, é uma dramaturgia viva.

Concluímos então que houveram, nesse evento, diferentes exemplos de possibilidades de manipulação de energia na prática da dança (treinamento e composição/criação). Enquanto Isabelle controlou a energia através da manipulação dos fatores de movimento (como acelerar e desacelerar o tempo, traçar o espaço e intensificar ou relaxar o corpo); Grácia compartilhou sua busca por desenvolver diferentes estados energéticos, através do uso de arquétipos que geram corporeidades específicas/características. Já Gustavo experimentou a energia gerada pelos acasos, pelo movimento de um grupo de pessoas movendo-se juntas, conduzidas em tempo real. Por sua vez, Holly trouxe uma exploração de energia que vem tanto do impulso interno do indivíduo (uso da gravidade), quanto de imagens que o corpo internaliza para auxiliar no movimento executado. Por fim, Sayonara experimentou o controle da energia e também um processo de dinamizar, dar forma a uma imagem impressa (fotografia) em jogo com a memória pessoal.

Com isso, lembramos que a formação artística/ técnica/ estética de cada artista influencia seu modo de criação (DANTAS, 2005; LOUPPE, 2010) e, portanto, a maneira com que ele propõe as organizações de ações do corpo em movimento. Através das experiências que tivemos com essas cinco práticas, com técnicas e estéticas distintas, confirmamos que cada uma tem seu modo particular de se manipular energia. Assim, nos alinhamos ao pensamento de Lehmann (2007) que enfatiza que dança não formula sentido, mas articula energia que emana do corpo vivo em cena, seja na sala de ensaio ou no palco. Enfim, propomos que nesta articulação reside a dramaturgia na dança, estando diretamente ligada às práticas e às técnicas que direcionam o processo de criação. Dramaturgia como energia que nasce no processo, é manipulada de acordo com a orientação técnica e estética de cada artista. Uma dramaturgia no processo a qual se mantém contemporânea nas práticas artísticas do presente. 
Referências

ALVIM, V. R. A dramaturgia na dança contemporânea brasileira: as experiências de colaboração entre coreógrafa e dramaturgista nos trabalhos de Lia Rodrigues e Silvia Soter. 2012. Dissertação (Mestrado) - Universidade Estadual de Campinas, Campinas, SP, Brasil, 2012.

ANDRADE, M. de. Danças dramáticas do Brasil. Edição Comemorativa (2002) ed. Belo Horizonte: Itatiaia Ed., 1959.

ARAUJO, A. O processo colaborativo no Teatro da Vertigem. Sala Preta, v. 6, p. 127-133, 2006.

ARISTÓTELES. Poética. Tradução Maria Helena da Rocha Pereira; Ana Maria Valente. Lisboa: Fundação Calouste Gulbenkian, 2007.

BARBA, E. Canoa de papel: tratado de antropologia teatral. São Paulo: Hucitec, 1994.

BARBA, E. An amulet made of memory: The Significance of Exercises in the Actor's Dramaturgy. TDR/The Drama Review, v. 41, n. 4, p. 127-132, 1997.

BONFITTO, M. Tecendo os sentidos: a dramaturgia como textura. Pitágoras 500 , v. 1, n. 1, p. 56-61, 2011.

BUTTERWORTH, J.; WILDSCHUT, L. (ed.). Contemporary choreography: a critical reader. Second edition ed. Milton Park, Abingdon, Oxon; New York, NY: Routledge, 2017.

CALDAS, P.; GADELHA, E. (ed.). Dança e dramaturgia[s]. Fortaleza: Nexus, 2016.
CALDAS, P.; GADELHA, E. Introdução. In: CALDAS, P.; GADELHA, E. (ed.). Dança e dramaturgia[s]. Fortaleza: Nexus, 2016. p. 10-17.

CORRADINI, S. Dramaturgia na dança: uma Perspectiva Coevolutiva entre Dança e Teatro. 2010. Universidade Federal da Bahia, Salvador, Brazil, 2010.

CRESPI, P.; MANGHANI, S. Rhythmanalysis: An Interview with Paola Crespi. Disponível em: <https://www.theoryculturesociety.org/rhythmanalysis-an-interview-with-paola-crespi/>. Acesso em: 20 abr. 2019.

DANTAS, M. De que são feitos os dançarinos de "aquilo..." criação coreográfica e formação de intérpretes em dança contemporânea. Movimento, v. 11, n. 2, p. 31-57, 2005.

DELAHUNTA, S. Dance Dramaturgy: speculations and reflections. Dance Theatre Journal, v. 16, n. 1, p. 20-25, 2000.

DORIA, G. Entrelaçando fios: possíveis eixos dramatúrgicos na Dança Contemporânea. Art Research Journal/Revista de Pesquisa em Arte, v. 3, n. 2, p. 194-208, dez. 2016.

DORT, B. L'tat d'esprit dramaturgique. Théâtre/Public, v. 67, p. 8-12, 1986.

ELIAS, M.; TOURINHO, L. L. Dramaturgias em Improvisação: Protocolos de Criação nas artes da cena. In: Xii Congresso Internacional da Abralic Centro, Centros- Ética, Estética. UFPR, Curitiba, Brasil. Anais[...] In:, Curitiba, Brasil: 18 jul. 2011. Disponível em: <http://www.abralic.org.br/ eventos/cong2011/AnaisOnline/resumos/ TC0786-1.pdf>. 
FURTADO, G. A Antropologia da Experiência na Dramaturgia do Ritmo. In: Primeiras jornadas de estudios de La Performance, Universidad Nacional de Córdoba. Anais[...] In: Córdoba: Universidad Nacional de Córdoba, 2012. Disponível em: <http://hdl.handle.net/11086/2406>. Acesso em: 30 mar. 2018.

GEORGELOU, K.; PROTOPAPA, E.; THEODORIDOU, D. The practice of dramaturgy: Working on Actions in Performance. Antennae: Arts in Society, 2017.

GREINER, C. Por uma dramaturgia da carne: o corpo como mídia da carne. Temas em contemporaneidade, imaginário e teatralidade GIPE-CIT, v. 11, n. 2, 2000.

HANSEN, P. Introduction. In: HANSEN, P.; CALLISON, D. (Ed.). Dance dramaturgy: modes of agency, awareness and engagement. Houndmills, Basingstoke Hampshire; New York, NY: Palgrave Macmillan, 2015. p. $1-27$.

HANSEN, P.; CALLISON, D. (ed.). Dance dramaturgy: modes of agency, awareness and engagement. Houndmills, Basingstoke Hampshire; New York, NY: Palgrave Macmillan, 2015.

KERKHOVE, M. van. Le processus dramaturgique. Nouvelles de Danse, Contredanse. v. 31, n. Bruxelles, p. 13-17, 1997.

LABAN, R. von. Domínio do movimento. Sao Paulo: Summus, 1978.

LEHMANN, H.-T. Teatro pós-dramático. Sao Paulo: Cosac Naify, 2007.
LEPECKI, A. Errância como Trabalho. In: CALDAS, P.; GADELHA, E. (Ed.). Dança e dramaturgia[s]. Fortaleza: Nexus, 2016. p. 61-84.

LOUPPE, L. Poetics of contemporary dance. Alton, Hampshire England: Dance Books, 2010.

MACEDO, V. F. de P. Pulsação da Obra: Dramaturgia nas Práticas Contemporâneas de Dança. 2016. Tese (Doutorado) - Universidade de São Paulo, São Paulo, 2016.

MILLER, J. Qual o Corpo que Dança? Dança e Educação Somática para Adultos e Crianças. Sao Paulo, Brasil: Summus, 2012.

MORAES, J. Repetição como estratégia de dramaturgia em dança. Revista Sala Preta, v. 12, n. 2, p. 86-104, dez 2012.

MUNDIM, A. C. (ed.). Dramaturgia do corpo-espaço e territorialidade. Uberlândia: Composer, 2012.

MUNDIM, A. C. Danças Brasileiras Contemporâneas: Um Caleidoscópio. São Paulo: Annablume, 2013.

OLIVEIRA, V. H. N. A Dramaturgia da Dança nas Manifestações Populares: Um Estudo Sobre a Dança de São Gonçalo de Amarante. In: 29a RBA Diálogos Antropológicos Expandindo Fronteiras, Anais[...] 2014. Disponível em: <http://www.29rba.abant.org. br/resources/anais/1/1401541055_ARQUIVO_ADRAMATURGIADADANCANASMANIFSTACOESPOPULARES.pdf>. Acesso em: 30 mar. 2018.

PETIT, L. The Michael Chekhov handbook: for the actor. Milton Park, Abingdon, Oxon; New York, NY: Routledge, 2010. 
ROUBINE, J.-J. Introdução às grandes teorias do teatro. Rio de Janeiro: J. Zahar, 2003.

SAADI, F. Dramaturgias: Estudo sobre a função do dramaturgista. Questão Crítica - Revista Eletrônica de Criticas e Estudos Teatrais, 27 dez. 2013. Disponível em: <http:// www.questaodecritica.com.br/2013/12/dramaturgias/>. Acesso em: 29 abr. 2018.

SCIALOM, M. Dramaturgia na dança: A Práxis de Rudolf Laban como Base para o Trabalho Dramaturgico em Dança. Cadernos GIPE-CIT, v. 16, p. 145-166, 2016.

SZATKOWSKI, J. A theory of dramaturgy. Abingdon, Oxon; New York, NY: Routledge, 2019.

SZONDI, P. Teoria do drama moderno: 1880-1950. São Paulo: Cosac \& Naify, 2001.

TURNER, J. Eugenio Barba. London; New York: Routledge, 2004.

VELLOSO, M. Dramaturgia na dança: investigação no corpo e ambientes de existência. Revista Sala Preta, v. 10, p. 191-197, 2010.

Recebido: $24 / 04 / 2019$

Aprovado: 22/10/2019 